OPEN ACCESS

Edited by:

Pan Xiong,

Nanjing University of Science and

Technology, China

Reviewed by:

Lishuang Fan,

Harbin Institute of Technology, China

Bing Sun,

University of Technology Sydney,

Australia

Liubing Dong,

Jinan University, China

*Correspondence:

Yu-Feng Qin

qinyufeng@sdau.edu.cn

${ }^{+}$These authors have contributed equally to this work

Specialty section: This article was submitted to

Electrochemistry,

a section of the journal

Frontiers in Chemistry

Received: 19 November 2021

Accepted: 13 December 2021

Published: 05 January 2022

Citation:

Ren L-L, Wang L-H, Qin Y-F and Li Q (2022) One-Pot Synthesized

Amorphous Cobalt Sulfide With

Enhanced Electrochemical

Performance as Anodes for Lithium-

Ion Batteries.

Front. Chem. 9:818255.

doi: 10.3389/fchem.2021.818255

\section{One-Pot Synthesized Amorphous Cobalt Sulfide With Enhanced Electrochemical Performance as Anodes for Lithium-Ion Batteries}

\author{
Long-Long Ren ${ }^{1 \dagger}$, Lin-Hui Wang ${ }^{2 \dagger}$, Yu-Feng Qin $^{2 *}$ and Qiang $\mathrm{Li}^{3}$ \\ ${ }^{1}$ College of Mechanical and Electronic Engineering, Shandong Agricultural University, Taian, China, ${ }^{2}$ College of Information \\ Science and Engineering, Shandong Agricultural University, Taian, China, ${ }^{3}$ College of Physics, University-Industry Joint Center for \\ Ocean Observation and Broadband Communication, Qingdao University, Qingdao, China
}

In order to solve the poor cycle stability and the pulverization of cobalt sulfides electrodes, a series of amorphous and crystalline cobalt sulfides were prepared by one-pot solvothermal synthesis through controlling the reaction temperatures. Compared to the crystalline cobalt sulfide electrodes, the amorphous cobalt sulfide electrodes exhibited superior electrochemical performance. The high initial discharge and charge capacities of 2,132 $\mathrm{mAh} / \mathrm{g}$ and $1,443 \mathrm{mAh} / \mathrm{g}$ at $200 \mathrm{~mA} / \mathrm{g}$ were obtained. The reversible capacity was 1,245 $\mathrm{mAh} / \mathrm{g}$ after 200 cycles, which is much higher than the theoretical capacity. The specific capability was $815 \mathrm{mAh} / \mathrm{g}$ at $800 \mathrm{~mA} / \mathrm{g}$ and increased to 1,047 mAh/g when back to 100 $\mathrm{mA} / \mathrm{g}$, indicating the excellent rate capability. The outstanding electrochemical performance of the amorphous cobalt sulfide electrodes could result from the unique characteristics of more defects, isotropic nature, and the absence of grain boundaries for amorphous nanostructures, indicating the potential application of amorphous cobalt sulfide as anodes for lithium-ion batteries.

Keywords: amorphous, cobalt sulfide, one-pot synthesis, anodes, lithium-ion batteries, high electrochemical performance

\section{INTRODUCTION}

Lithium-ion batteries (LIBs) have been wildly used in small consumer electronics, electric vehicles, and medical apparatus as energy storage devices due to their advantages of high energy density, long cycle life, high working voltage, no memory effect, small self-discharge, and wide operating temperature range (Sun et al., 2010; Wang et al., 2020c; Gu et al., 2021; Li et al., 2021a; Li et al., 2021b; Li et al., 2021c; Li et al., 2021d; Zhao et al., 2021; Liang et al., 2022). However, to apply in largescale energy storage projects and other high-power systems, the electrochemical properties of power density, rate capacity, cycle stability, and safety issue should be further improved (Sun et al., 2011; Zhang et al., 2019b; Wang et al., 2020b; Zhang et al., 2020a; Wang et al., 2021b). Current commercial graphite anode materials exhibit the advantages of high energy density, high conductivity, and security. Still, their low theoretical capacity of $372 \mathrm{mAh} / \mathrm{g}$ and poor rate capability have confined the further development of LIBs(Zhang et al., 2019a; Hou et al., 2020; Li et al., 2020b; Gao et al., 2021; Wang et al., 2021a). Therefore, it is urgent to develop high-performance anode materials to meet the high power energy needs in the future (Zhao et al., 2019; Zhao et al., 2020; Liu et al., 2021a). It has long been discovered that cobalt sulfides $\left(\mathrm{CoS}, \mathrm{CoS}_{2}, \mathrm{Co}_{3} \mathrm{~S}_{4}, \mathrm{Co}_{9} \mathrm{~S}_{8}\right)$ have lithium storage ability and 
high reversible capacities (Yan et al., 2005; Shi et al., 2012; Gu et al., 2013). In order to achieve the practical application of cobalt sulfides as anode materials, the intrinsic drawbacks of low conductivity and significant volume expansion during cycles must be solved (Gu et al., 2013; Jiang et al., 2020). Many different crystalline nanostructures and morphologies have been designed and prepared to relieve the decomposition caused by the volume expansion. Carbon-based materials have also been introduced to increase the conductivity (Yan et al., 2005; Shi et al., 2012; Gu et al., 2013; Jiang et al., 2020). Yang et al. reported that the cubic phase of $\mathrm{CoS}_{2}$ was prepared by calcination at high temperature and exhibited the initial discharge capacity of $1,280 \mathrm{~mA} \mathrm{~h} / \mathrm{g}$ and the reversible capacity of $350 \mathrm{~mA} \mathrm{~h} / \mathrm{g}$ after ten cycles at $50 \mathrm{~mA} / \mathrm{g}$ (Yan et al., 2005). Yan et al. prepared carboncoated $\mathrm{Co}_{9} \mathrm{~S}_{8}$ nano-dandelions by a facile solvothermal method, and the high reversible capacity of $520 \mathrm{~mA} \mathrm{~h} / \mathrm{g}$ at the current density of $1 \mathrm{~A} / \mathrm{g}(1.8 \mathrm{C})$ after the 50th cycle was obtained (Shi et al., 2012). Wang et al. prepared standard hexagonal CoS nanocomposites wrapped by graphene by a solvothermal method. The CoS nanocomposites exhibited a high reversible capacity of $749 \mathrm{~mA} \mathrm{~h} / \mathrm{g}$ after 40 cycles at $62.5 \mathrm{~mA} / \mathrm{g}$ ( $\mathrm{Gu}$ et al., 2013). Wei et al. prepared the polycrystalline $\mathrm{Co}_{9} \mathrm{~S}_{8} / \mathrm{C}$ composites by an electrospinning method, and the electrodes exhibited an initial discharge capacity of $823 \mathrm{~mA} \mathrm{~h} / \mathrm{g}$ and a reversible capacity of 1,063 mA h/g after 200 cycles at $300 \mathrm{~mA} / \mathrm{g}$ (Jiang et al., 2020). Even though good electrochemical performance has been observed in these crystalline cobalt sulfides, the poor cycle stability and the pulverization of the materials caused by the volume expansion still exist. Therefore, it is necessary to find a new way to solve these problems. Amorphous nanostructures always have more defects, which will provide more active sites. Furthermore, the isotropic nature and the absence of grain boundaries for amorphous nanostructures could improve the capacity to sustain high strain and the insertion of lithium ions, which is helpful to inhibit the volume expansion (Liu et al., 2013; Lu et al., 2018; Wu et al., 2019; Duan et al., 2021; Wu et al., 2021). Zhao et al. reported that the amorphous $\mathrm{VO}\left(\mathrm{PO}_{3}\right)_{2}$ exhibited a high initial discharge capacity of $1,297 \mathrm{~mA} \mathrm{~h} / \mathrm{g}$ and a reversible capacity of $676 \mathrm{~mA} \mathrm{~h} / \mathrm{g}$ after 150 cycles at the current of $100 \mathrm{~mA} /$ $\mathrm{g}$, which is much higher than those of crystalline $\mathrm{VO}\left(\mathrm{PO}_{3}\right)_{2}$ due to the isotropic ions diffusion paths (Wu et al., 2021). Wu et al. reported that amorphous $\mathrm{V}_{2} \mathrm{O}_{3} / \mathrm{C}$ composite exhibited higher reversible capacity and superior cycling stability than crystalline $\mathrm{V}_{2} \mathrm{O}_{3} / \mathrm{C}$ composite, which accounted for the oxygen vacancies and amorphous phase (Wu et al., 2019). Yang et al. reported that compared to the crystalline Sn@C anodes, better rate capability, longer cycle life, and higher capacity had been observed for amorphous Sn@C anodes because of the defect sites and the improved strain regulation (Duan et al., 2021). However, as far as we know, the amorphous anode materials have not been systematically investigated, and the amorphous cobalt sulfides anode materials for LIBs have not been reported.

In this work, a series of amorphous and crystalline cobalt sulfide nanomaterials were prepared by a facile solvothermal method at different reaction temperatures. Due to the unique characteristics of more defects, isotropic nature, and the absence of grain boundaries for amorphous nanostructures, the amorphous cobalt sulfide exhibited superior electrochemical performance compared to the crystalline cobalt sulfide. The initial discharge and charge capacities of the amorphous samples are $2,132 \mathrm{mAh} / \mathrm{g}$ and $1,443 \mathrm{mAh} / \mathrm{g}$, respectively, at $200 \mathrm{~mA} / \mathrm{g}$. The Coulombic efficiency sharply increased to $97.44 \%$ in the second cycle and maintained near $100 \%$ to the $200^{\text {th }}$ cycle. The high reversible capacity of $1,245 \mathrm{mAh} / \mathrm{g}$ after 200 cycles was observed. The specific capability was $815 \mathrm{mAh} / \mathrm{g}$ at $800 \mathrm{~mA} / \mathrm{g}$ and increased to $1,047 \mathrm{mAh} / \mathrm{g}$ when back to $100 \mathrm{~mA} / \mathrm{g}$, indicating the excellent rate capability. The amorphous cobalt sulfide nanomaterials with outstanding electrochemical performance have the potential application as anodes for LIBs.

\section{EXPERIMENTAL SECTION}

\section{Materials and Batteries}

The schematic illustration of preparing CoS (amorphous and crystalline) materials and the assembling of the half cells (CR2032) is shown in Figure 1. The cobalt sulfide nanomaterials were prepared as follows. $713.79 \mathrm{mg}(3 \mathrm{mmol})$ of $\mathrm{CoCl}_{2} \cdot 6 \mathrm{H}_{2} \mathrm{O}$ were added into $70 \mathrm{ml}$ of ethylene glycol and magnetically stirred for $2 \sim 3 \mathrm{~h} .89 .7 \mathrm{mg}$ ( $4 \mathrm{mmol})$ of L-cysteine were added consequently and magnetically stirred for another $2 \sim 3 \mathrm{~h}$ to dissolve completely. The mixed solution was divided into two Teflon-lined autoclaves $(50 \mathrm{ml})$ and put in an air blast drying cabinet for $24 \mathrm{~h}$ at different reaction temperatures of $140^{\circ} \mathrm{C}, 160^{\circ} \mathrm{C}, 180^{\circ} \mathrm{C}$, and $200^{\circ} \mathrm{C}$, respectively. After the precipitates were alternately washed with deionized water and absolute alcohol several times, the precipitates were dried in a vacuum drying oven at $60^{\circ} \mathrm{C}$ for $12 \mathrm{~h}$. Finally, the amorphous and crystalline cobalt sulfide nanomaterials were obtained. According to the reaction temperatures, the as-prepared cobalt sulfide nanomaterials were denoted by CoS-140, CoS-160, CoS-180, and CoS-200, respectively.

The cobalt sulfide nanomaterials, carbon black, and binder were mixed at a weight of 7:2:1 and roundly ground. The binder is carboxymethyl cellulose (CMC) dissolved in deionized water with a weight ratio of $10 \%$. The black slurry was smeared evenly on the copper foil and then dried in a vacuum drying oven at $60^{\circ} \mathrm{C}$ for $12 \mathrm{~h}$. The copper foil was punched into many disks with an area of $113 \mathrm{~mm}^{2}$. The average loading mass of the active materials is $0.82 \mathrm{mg} / \mathrm{cm}^{2}$. Finally, the half cells were assembled with the copper disks and the lithium metal foil in an argonfilled glove box. The diaphragm and electrolyte are the Celgard 2,250 film and 1M LiPF6 dissolved in a mixed solution of ethyl carbonate and dimethyl ethyl carbonate with a volume ratio of $1: 1$.

\section{Structure and Morphology}

The structure was characterized by X-ray diffraction (XRD, Smart Lab, Rigku Japan) in the range of $20^{\circ}-80^{\circ}$ using a $\mathrm{Cu} \mathrm{Ka}$ radiation. The morphology was further identified by a scanning electron microscope (SEM, GeminiSEM300, Zeiss, Germany). 


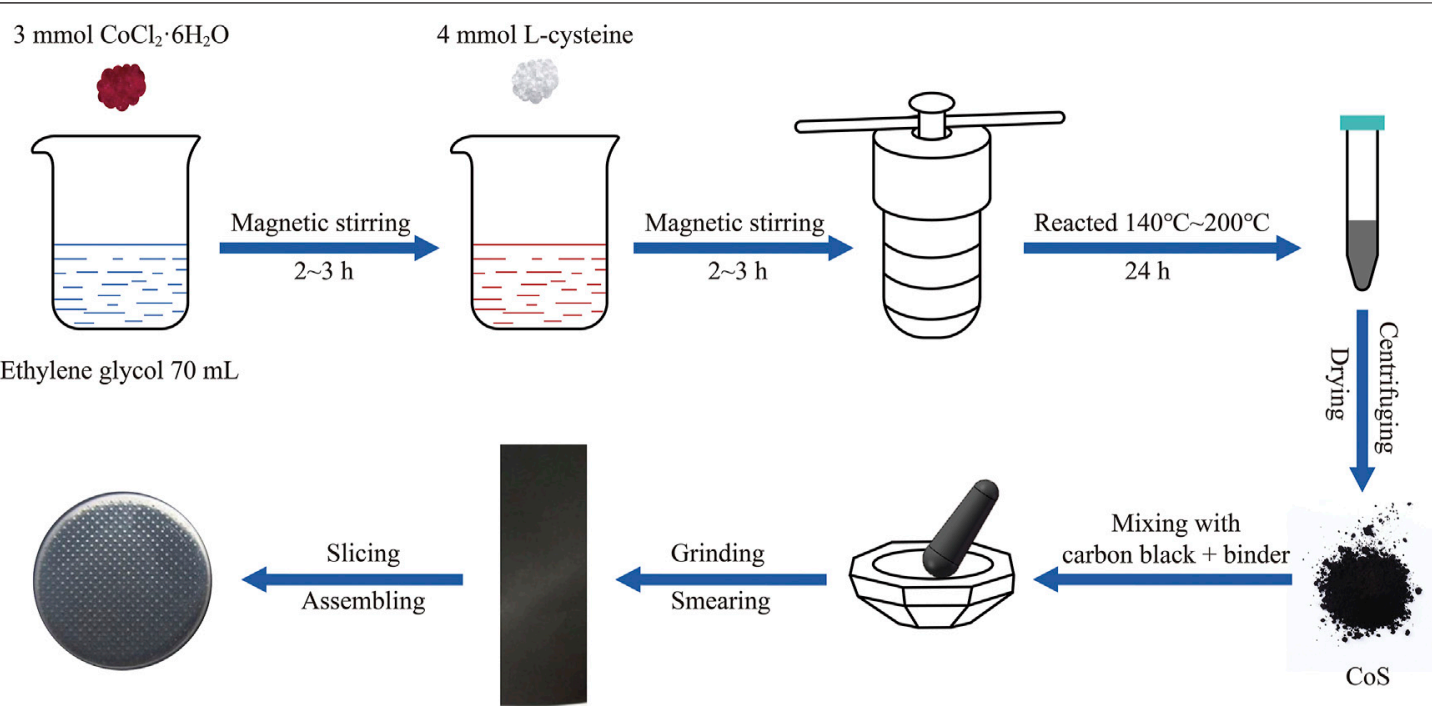

FIGURE 1 | The schematic illustration of preparing the CoS materials and assembling half cells.

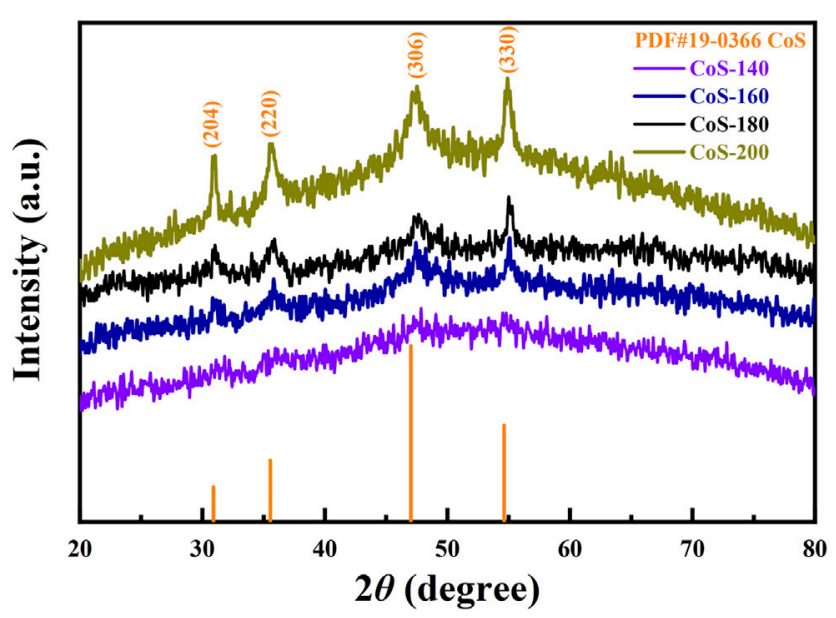

FIGURE 2 | The XRD patterns of the CoS samples prepared at different temperatures.

\section{Electrochemical Performance Characterization}

The electrochemical performance and impedance characteristics were measured by battery measuring systems (Land-ct2001A, China) and electrochemical workstation (CHI660E, China) in the potential range of $0.01-3.0 \mathrm{~V}$ at room temperature.

\section{RESULTS AND DISCUSSION}

\section{Structure and Morphology}

The XRD patterns of the as-prepared materials reacted at different temperatures are shown in Figure 2. With the increase of the reaction temperatures, the diffraction peaks gradually become apparent. No diffraction peak is observed for the CoS-140 sample, indicating the amorphous or nanocrystalline structure due to low reaction temperature. The diffraction peaks gradually appear, and the intensities increase gradually for the CoS-160 and CoS-180 samples, which indicates a progressively crystallized process with the increase of the reaction temperatures. For the CoS-200 sample, the diffraction peaks are very remarkable, which means good crystallization. The diffraction peaks at $31.05^{\circ}, 35.68^{\circ}, 47.13^{\circ}$, and $54.91^{\circ}$ are consistent with the standard card of PDF No. 19-0366 $\left(\mathrm{CoS}_{1.097}\right)$, and these peaks correspond to the (204), (220), (306) and (330) crystal planes of hexagonal $\mathrm{CoS}_{1.097}$, respectively. In addition, no other diffraction peaks are observed, indicating the pure cobalt sulfide nanomaterials of our samples. The degree of crystallization increases with the reaction temperatures. A series of amorphous and crystalline cobalt sulfide nanomaterials were prepared by controlling the reaction temperatures.

The morphologies of the amorphous and crystalline cobalt sulfide nanomaterials can be determined by the SEM images shown in Figure 3. From Figure 3A, the morphology of the amorphous CoS-140 sample is rough and irregular with many pits on the surface, and there are no noticeable regular crystalline grains observed, which is consistent with the absence of pronounced diffraction peaks shown in Figure 2. For the CoS160 sample, some regular nanospheres are observed on the rough surface. And the regular nanospheres with different diameters should be crystalline structures. While for the CoS-180 sample, in addition to the regular nanospheres, some cracks are observed on the surface, which could result from the growth of the crystalline grains. A lot of small regular nanoparticles are observed for the CoS-200 sample, indicating crystalline growth of the sample, which strongly consists with the obvious diffraction peaks shown in Figure 2. Controlling reaction temperatures is crucial to synthesizing the cobalt sulfide nanomaterials with different amorphous or crystalline structures. 

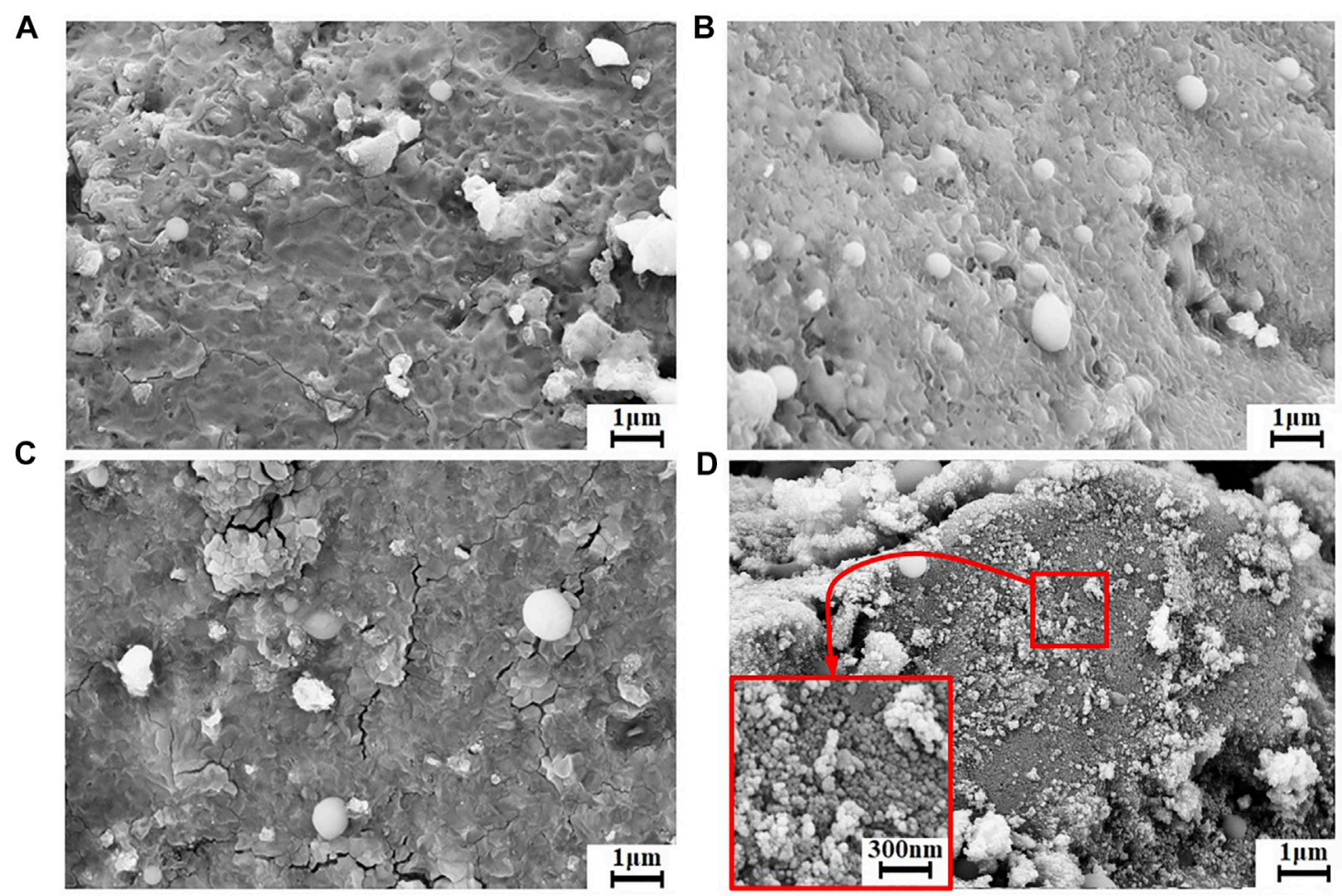

FIGURE 3 | The SEM images of CoS-140 (A), CoS-160 (B), CoS-180 (C), and CoS-200 (D).

\section{Electrochemical Performance}

In order to compare the electrochemical performance of the series of amorphous and crystalline cobalt sulfide nanomaterials, the cycle performance at $200 \mathrm{~mA} / \mathrm{g}$ and the rate capability at different current densities were measured and shown in Figure 4. From Figure 4A, the samples of the CoS-140 and CoS-160 exhibit the relative constant reversible capacities, which indicates better cycle stability than that of the crystalline cobalt sulfide samples (CoS-160 and CoS-200). For the CoS-180 and CoS-200 samples, the specific capacities decrease first and then increase with the cycles, which is very common for the crystalline transition metal sulfides electrodes (Zhou et al., 2015). The first decrease could be due to the evolution of the SEI layers and the insufficient reaction of some active sites, and the subsequent increase could result from the polymeric gel-like layer and the decomposition of the crystal structure of $\mathrm{CoS}$ nanoparticles during the dischargecharge cycles (Zhou et al., 2020). However, the specific capacity of the CoS-200 sample decreases more sharply and obviously in the first cycles, which could result from the rapid decomposition of the crystalline structure during the cycles (Zhou et al., 2015; Wang et al., 2020b; Jiang et al., 2020). The CoS-140 sample exhibits the best cycling stability with the initial discharge and charge capacities of $2,132 \mathrm{mAh} / \mathrm{g}$ and $1,443 \mathrm{mAh} / \mathrm{g}$, respectively. The Coulombic efficiency in the first cycle is $67.67 \%$ and radically increases to $97.44 \%$ in the second cycle, and maintains near $100 \%$ to the $200^{\text {th }}$ cycle. Significantly, the reversible capacity of $1,245 \mathrm{mAh} / \mathrm{g}$ after 200 cycles was obtained, which is much higher than the theoretical capacity of $589 \mathrm{mAh} / \mathrm{g}$ (Yan et al., 2005). The initial discharge capacity and the reversible capacity in this work and those of other reported cobalt sulfide-based electrodes are listed in Table 1, which indicates the outstanding electrochemical performance of the amorphous sample of CoS- 140 .

From Figure 4B, the samples of the CoS-140 and CoS-160 also exhibit better rate capability than that of the crystalline cobalt sulfide, which is consistent with the results of the cycle performance shown in Figure 4A. Even though the reversible capacity returns to $658 \mathrm{~mA} \mathrm{~h} / \mathrm{g}$ when the current density goes back to $100 \mathrm{~mA} / \mathrm{g}$, the crystalline sample of CoS-200 exhibits the worst rate capability than other samples. The details of the average reversible capacities for the series of cobalt sulfide nanomaterials at different current densities are listed in Table 2, which also indicates the best rate capability of the amorphous sample of CoS-140 at each current density. The reversible capabilities of the amorphous CoS-140 sample are $1,450 \mathrm{mAh} / \mathrm{g}, \quad 1,170 \mathrm{mAh} / \mathrm{g}, 958 \mathrm{mAh} / \mathrm{g}$, and $815 \mathrm{mAh} / \mathrm{g}$ at $100 \mathrm{~mA} / \mathrm{g}, \quad 200 \mathrm{~mA} / \mathrm{g}, \quad 500 \mathrm{~mA} / \mathrm{g}$, and $\quad 800 \mathrm{~mA} / \mathrm{g}$, and the capabilities increase to $889 \mathrm{mAh} / \mathrm{g}, 1,015 \mathrm{mAh} / \mathrm{g}$, and $1,047 \mathrm{mAh} / \mathrm{g}$ when back to $500 \mathrm{~mA} / \mathrm{g}, 200 \mathrm{~mA} / \mathrm{g}$, and $100 \mathrm{~mA} / \mathrm{g}$, indicating the excellent rate capability. The outstanding electrochemical performance of the amorphous sample could result from the more active sites due to the more defects and the improved ability of the volume accommodation because of the isotropic nature and the absence of grain boundaries for the amorphous structure (Li et al., 2012; Liu et al., 2013; Wu et al., 2019; Wang et al., 2020b; Duan et al., 2021; Wu et al., 2021).

Due to the best electrochemical performances, further investigation was focused on the amorphous CoS-140 sample. In order to comprehend the electrochemical reaction mechanism, the 


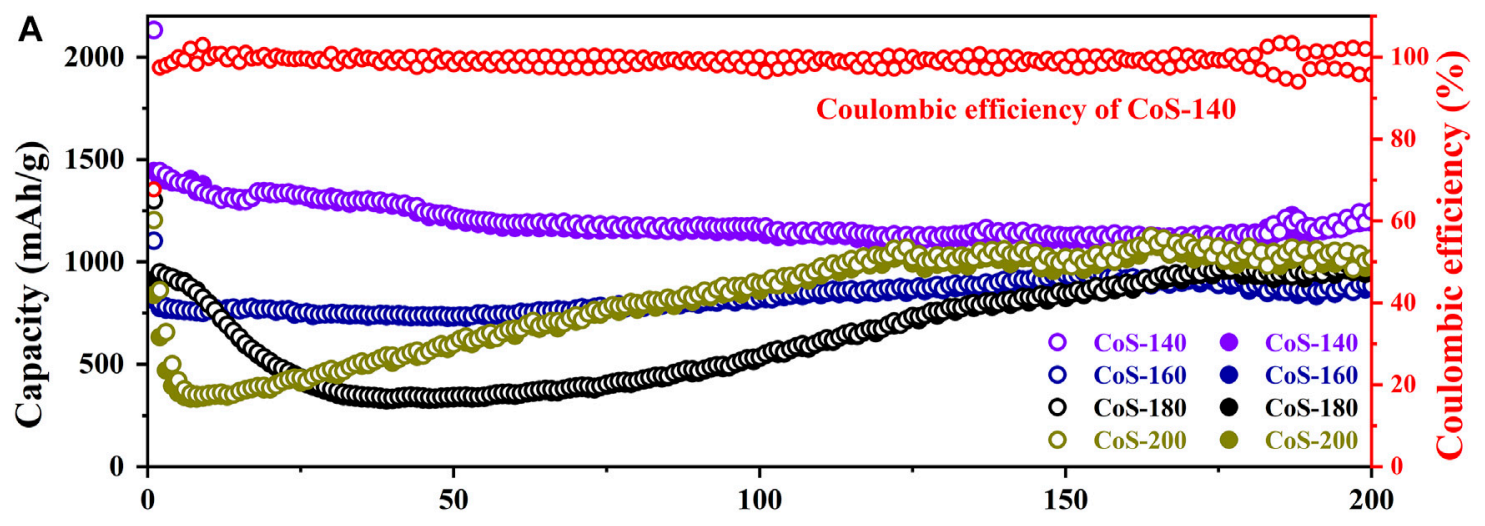

Cycle Number

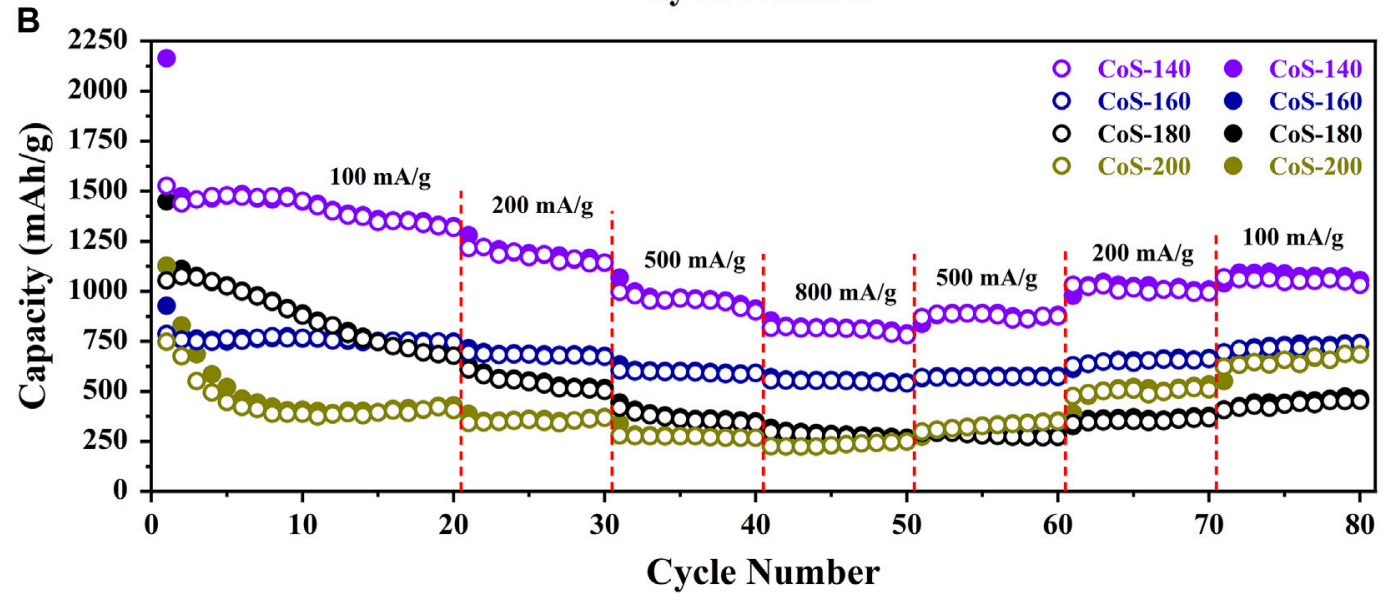

FIGURE 4 | The cycle stabilities at $200 \mathrm{~mA} / \mathrm{g}$ (A) and rate capabilities (B) of the CoS samples prepared at different temperatures. The solid and hollow circles represent the discharge and charge capacities, respectively.

TABLE 1 | The comparison of the electrochemical performance between this work and other reported cobalt sulfide-based electrodes.

\begin{tabular}{|c|c|c|c|c|}
\hline Materials & $\begin{array}{l}\text { Initial discharge capacity } \\
\qquad(\mathrm{mAh} / \mathrm{g})\end{array}$ & Reversible capacity (mAh/g) & Current density (mA/g) & References \\
\hline Amorphous CoS & 2,132 & 1,443 (200 cycles) & 200 & This work \\
\hline Crystalline CoS & 1,205 & 1,017 (200 cycles) & & \\
\hline $\mathrm{C} @ \mathrm{Co}_{9} \mathrm{~S}_{8}$ & 848 & 520 (50 cycles) & $1.8 \mathrm{C}$ & Shi et al. (2012) \\
\hline $\mathrm{CoS}_{2}$ & 1,280 & 350 (50 cycles) & 50 & Yan et al. (2005) \\
\hline CoS/graphene & 1,669 & 749 (40 cycles) & $0.1 \mathrm{C}$ & Gu et al. (2013) \\
\hline $\mathrm{Co}_{9} \mathrm{~S}_{8} / \mathrm{C}$ & 2026 & 1,063 (200 cycles) & 300 & Jiang et al. (2020) \\
\hline $\mathrm{Cog}_{8}-650 @ \mathrm{C}$ & 1,584 & 1,414 (100 cycles) & 100 & Zhou et al. (2015) \\
\hline $\mathrm{CoS}_{2} \mathrm{NP} @ \mathrm{G}-\mathrm{CoS}_{2}$ & 1,504 & 1,022 (50 cycles) & 100 & He et al. (2015) \\
\hline CoS-NP/ACFs & $1,137.3$ & 576.7 (200cycles) & 100 & Yuan et al. (2020b) \\
\hline $\mathrm{CoS}_{2}-\mathrm{C} / \mathrm{CNT}$ & 1,339 & 1,030 (120 cycles) & 100 & Ma et al. (2018) \\
\hline $\mathrm{Co}_{3} \mathrm{~S}_{4} / \mathrm{CNF}$ & 991 & 742 (200 cycles) & 1,000 & Luo et al. (2019) \\
\hline $\mathrm{Si@C-CogS} / \mathrm{C}$ & 1,441 & 1,399 (200 cycles) & 100 & Yuan et al. (2020a) \\
\hline CMF@ $\mathrm{Co}_{9} \mathrm{~S}_{8}-\mathrm{C}$ & 1,315 & 615 (450 cycles) & 500 & Zhang et al. (2020) \\
\hline $\mathrm{Co}_{4} \mathrm{~S}_{3} / \mathrm{CNA} @ \mathrm{CC}$ & 1,200 & 720 (200 cycles) & 1,000 & Shi et al. (2020) \\
\hline $\mathrm{Co}_{9} \mathrm{~S}_{8}$ & 1,100 & 910 (100 cycles) & 500 & Lu et al. (2017) \\
\hline CNTs@NC & 1,366 & 914 (100 cycles) & 100 & Wang et al. (2020a) \\
\hline $\mathrm{Co}_{9} \mathrm{~S}_{8} / \mathrm{Ni}$ & 1,580 & 720 (100 cycles) & 100 & Jin et al. (2016) \\
\hline $\mathrm{CoS}_{2}$ & 1,542 & 737 (200 cycles) & 1,000 & Yu et al. (2016) \\
\hline $\mathrm{CoS}_{2} \mathrm{NG}$ & 1,120 & 1,018 (50 cycles) & 100 & Qiu et al. (2015) \\
\hline $\mathrm{CoS}_{2}$ & 1,416 & 883 (100 cycles) & 100 & Jin et al. (2015) \\
\hline
\end{tabular}


TABLE 2 | The reversible capacities of the CoS samples at different current densities.

\begin{tabular}{|c|c|c|c|c|c|c|c|}
\hline Samples & $100 \mathrm{~mA} / \mathrm{g}$ & $200 \mathrm{~mA} / \mathrm{g}$ & $500 \mathrm{~mA} / \mathrm{g}$ & $800 \mathrm{~mA} / \mathrm{g}$ & $500 \mathrm{~mA} / \mathrm{g}$ & $200 \mathrm{~mA} / \mathrm{g}$ & $100 \mathrm{~mA} / \mathrm{g}$ \\
\hline CoS-140 & 1,451 & 1,170 & 958 & 815 & 889 & 1,015 & 1,047 \\
\hline CoS-160 & 766 & 684 & 595 & 551 & 572 & 643 & 723 \\
\hline CoS-180 & 879 & 546 & 361 & 279 & 280 & 347 & 434 \\
\hline CoS-200 & 389 & 357 & 276 & 230 & 326 & 485 & 658 \\
\hline
\end{tabular}
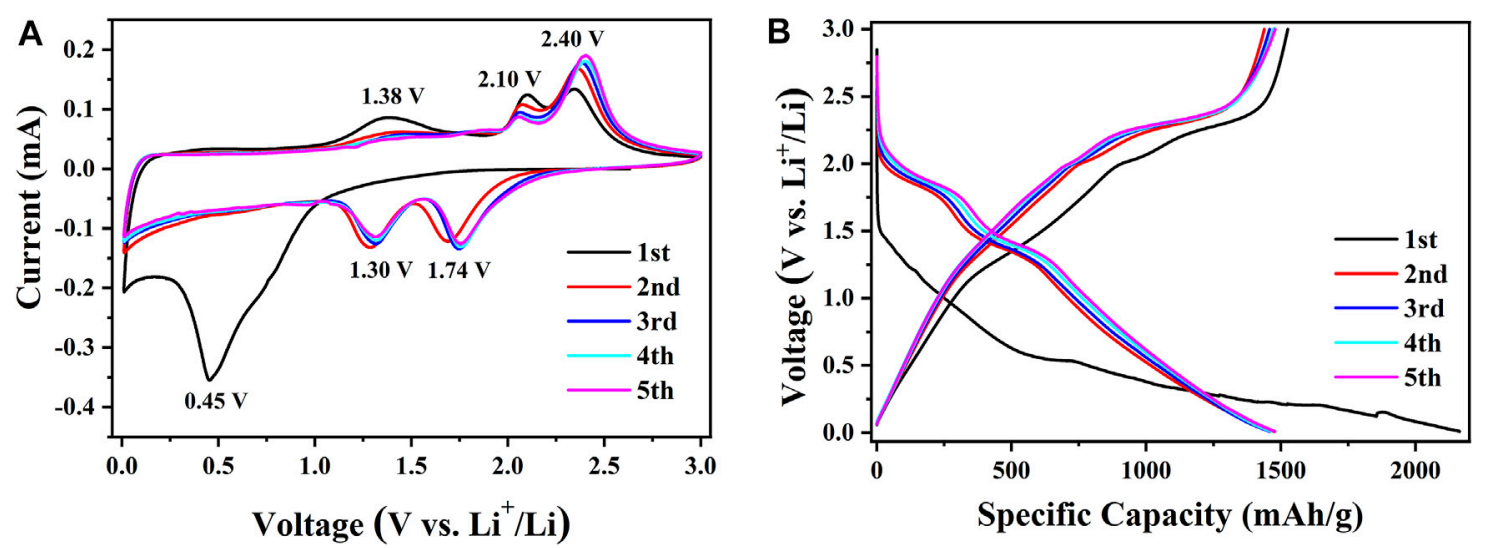

FIGURE 5 | The first five CV curves at $0.1 \mathrm{~m} \mathrm{V/s} \mathrm{(A)} \mathrm{and} \mathrm{the} \mathrm{first} \mathrm{five} \mathrm{discharge-charge} \mathrm{curves} \mathrm{at} 100 \mathrm{~mA} / \mathrm{g}$ (B) for the amorphous CoS-140 sample.

first five voltammetry (CV) curves of the amorphous CoS-140 sample were measured at a scan rate of $0.1 \mathrm{mV} / \mathrm{s}$, as is shown in Figure 5A. In the first discharge process, there is a broad reduction peak at $0.45 \mathrm{~V}$, which relates to the formation of the solid electrolyte interface (SEI) and the process of cobalt sulfide reduced to cobalt metal and $\mathrm{Li}_{2} \mathrm{~S}$ (He et al., 2015; Zhou et al., 2015; Yuan et al., 2020b). In the following cathodic sweeps, the broad peak divides into two sharp peaks located at 1.74 and $1.30 \mathrm{~V}$, which correspond to the formation of $\mathrm{Li}_{x} \mathrm{CoS}$ and the further convention reaction of $\mathrm{Li}_{x} \mathrm{CoS}$ to Co. metal (Ma et al., 2018; Yuan et al., 2020b). There is a broad peak at $1.38 \mathrm{~V}$ in the first charge process, which consists with the decomposition of the SEI layer (Zhou et al., 2015; Ma et al., 2018). This broad peak almost disappears in the following cycles due to the stability of the SEI layer, which is beneficial for the cycle stability (Zhou et al., 2015; Ma et al., 2018). There are also two oxidation peaks around 2.10 and $2.40 \mathrm{~V}$ in the five cathodic sweeps, which are consistent with the above reversible reactions of extraction of lithium ions to form $\mathrm{CoS}$ and the reduction process of $\mathrm{Li}_{2} \mathrm{~S}$ to $\mathrm{S}$ (Zhou et al., 2015; Ma et al., 2018; Luo et al., 2019; Yuan et al., 2020b). The tiny changes of the positions for the two reduction peaks (1.74 and $1.30 \mathrm{~V})$ and the two oxidation peaks $(2.10$ and $2.40 \mathrm{~V})$ could result from a slight transformation of the structure (Zhou et al., 2015; Luo et al., 2019). The oxidation and reduction peaks almost coincide after the first cycle, indicating the stable electrochemical reaction process. The approximate overlap of the CV curves after the first cycle also shows excellent cycle stability and reversibility (Ma et al., 2018; Luo et al., 2019; Yuan et al., 2020b).

The first five discharge-charge curves at $100 \mathrm{~mA} / \mathrm{g}$ are also shown in Figure 5B to compare the results of the CV curves. An extended voltage plateau from 0.63 to $0.15 \mathrm{~V}$ can be observed in the first discharge curves, which corresponds to the broad reduction peak at $0.45 \mathrm{~V}$ in the first $\mathrm{CV}$ cathodic sweep. There are two discharge plateaus around $2.10-1.70 \mathrm{~V}$ and $1.45-1.25 \mathrm{~V}$ in the following discharge curve, which consist with the division of the peak of $0.45 \mathrm{~V}$ into two peaks of 1.74 and $1.30 \mathrm{~V}$. For the first charge curve, there are three plateaus around $1.20 \mathrm{~V}-2.00 \mathrm{~V}, 2.00 \mathrm{~V}-2.20 \mathrm{~V}$, and 2.20-2.46 V, corresponding to the three peaks of $1.36,2.10$, and $2.40 \mathrm{~V}$ in the first anodic sweep. The voltage plateau of $1.20-2.00 \mathrm{~V}$ disappears in the following cycles, indicating the stability of the SEI layer, which is in agreement with the disappearance of the oxidation peak at $1.38 \mathrm{~V}$. After the initial cycle, the discharge-charge curves nearly overlap, which indicates the high reversible cycle stability and the reversible redox reactions of the amorphous sample.

In order to deeply comprehend the enhanced electrochemical performance and the reaction kinetics of the amorphous CoS-140 sample, the electrochemical impedance spectroscopies (EIS) were measured from $10^{-2} \mathrm{~Hz}-10^{5} \mathrm{~Hz}$ before and after cycling, as is shown in Figure 6. Both the two Nyquist plots (black scatters) are composed of one depressed semicircle in high-frequency regions and one straight line in low-frequency regions, which can be well fitted by the equivalent circuit (red fitting lines) that is shown in the inset of Figure 6A. In the equivalent circuit, the parameter of $R_{\mathrm{s}}$ denotes the ohmic resistance of the electrode and electrolyte, and the parameter of $R_{\mathrm{ct}}$ signifies the charge transfer resistance (Wu et al., 2019; Duan et al., 2021; Wu et al., 2021). The fitted $R_{\mathrm{ct}}$ after cycling $(229.5 \Omega)$ is much lower than that of before cycling $(7645 \Omega)$, indicating the higher reaction kinetics activity during the cycles, which is in agreement with the excellent cycle stability and the rate capability shown in Figure 4. Moreover, the Li-ions diffusion coefficient $\left(\mathrm{D}_{\mathrm{Li}^{+}}\right)$can be obtained by the following equations (Wang et al., 2020b; Duan et al., 2021). 

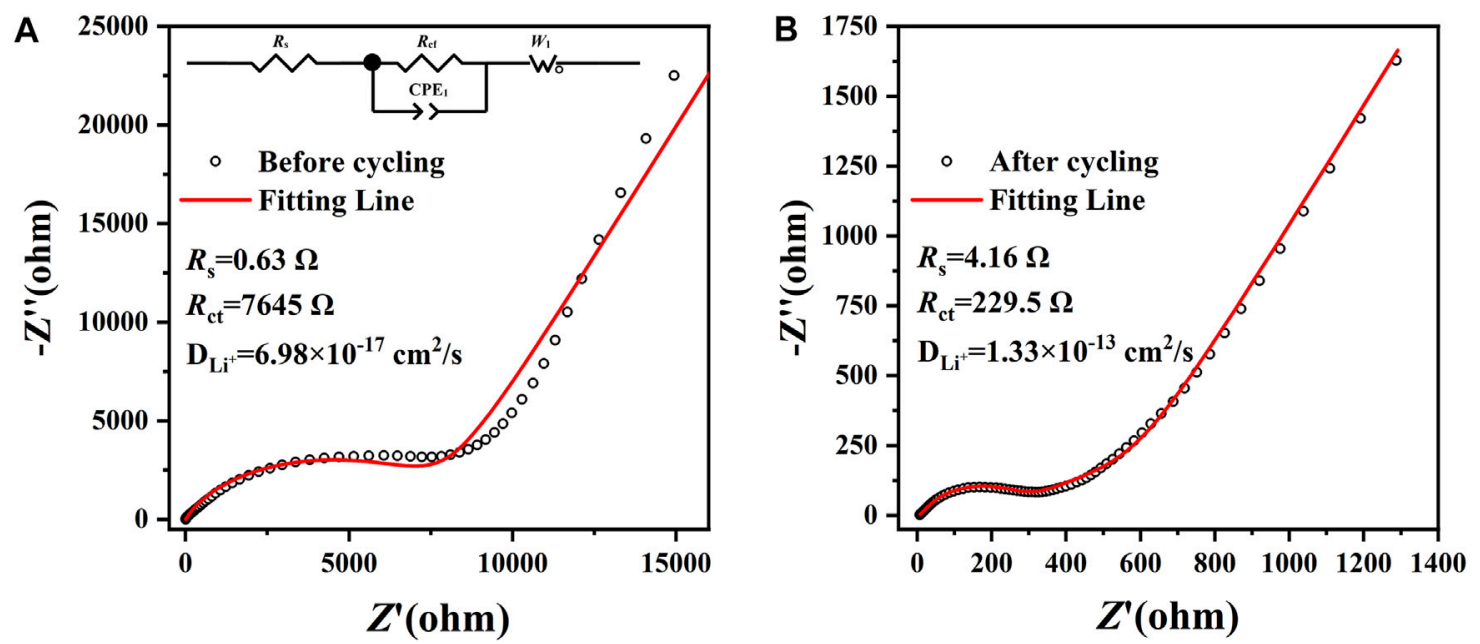

FIGURE 6 | The EIS of the amorphous CoS-140 sample before (A) and after (B) cycling from $10^{-2} \mathrm{~Hz}-10^{5} \mathrm{~Hz}$. The equivalent circuit is shown in the inset of (A).

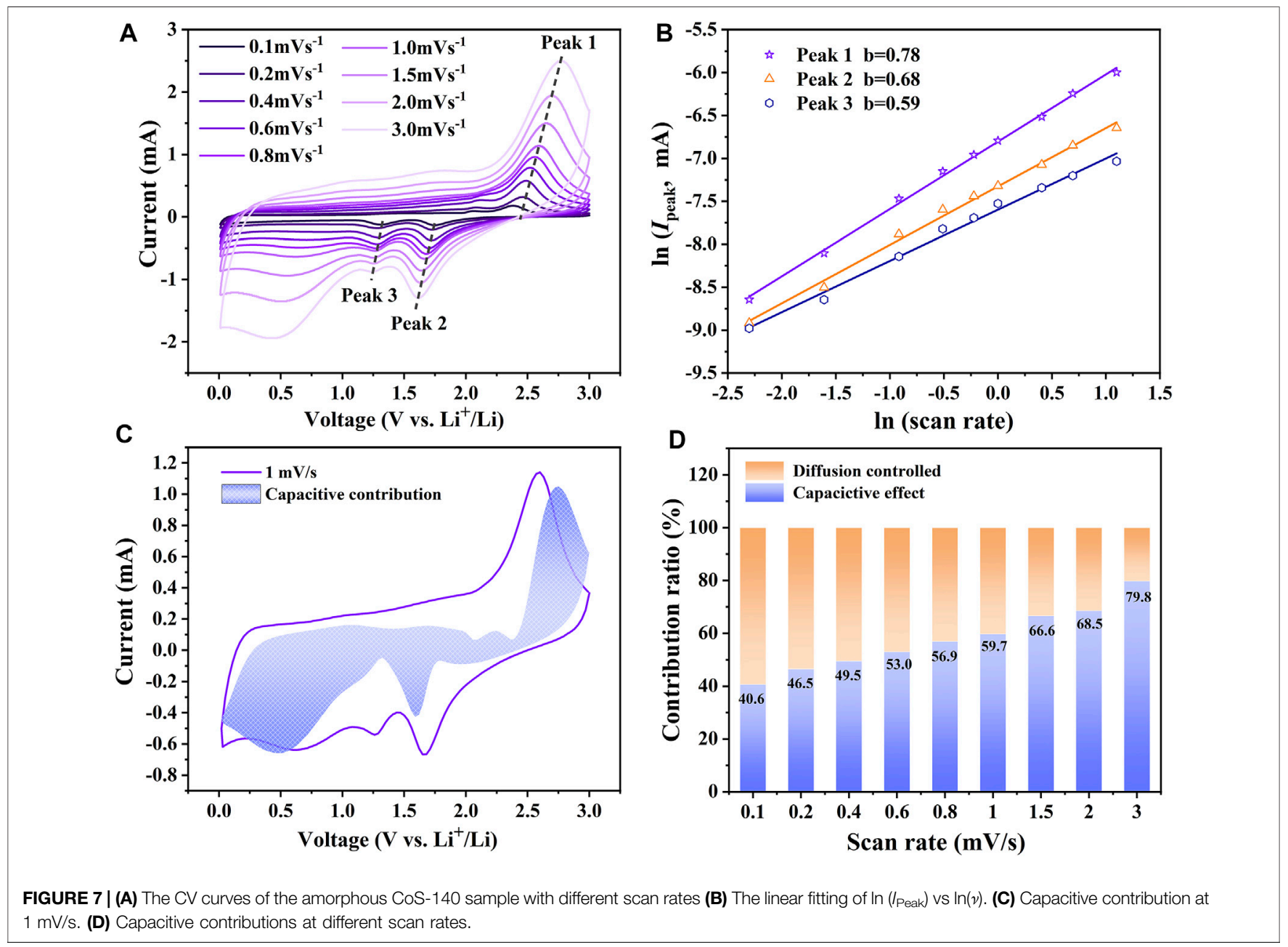




$$
\begin{gathered}
D_{\mathrm{Li}^{+}}=\frac{R^{2} T^{2}}{2 A^{2} n^{4} F^{4} C^{2} \sigma^{2}} \\
Z_{\text {real }}=R_{\mathrm{s}}+R_{\mathrm{ct}}+\sigma \omega^{-1 / 2}
\end{gathered}
$$

The parameters of $R, T, A, n, F, C, \sigma$, and $\omega$ are the general physical parameters gas constant, the measuring temperature, the surface area of the electrode, the number of transferred electrons, the Faraday constant, the concentration of lithium ions, the Warburg coefficient, and the angular frequency, respectively (Wang et al., 2020b; Yuan et al., 2020b). The value of $\sigma$ could be fitted by Eq. 2 according to the EIS data in the low-frequency regions, and then the Li-ions diffusion coefficient can be calculated by Eq. 1. The Li-ions diffusion coefficient after cycling $\left(1.33 \times 10^{-13} \mathrm{~cm}^{2} / \mathrm{s}\right)$ is much higher than before cycling $\left(6.98 \times 10^{-17} \mathrm{~cm}^{2} / \mathrm{s}\right)$, which also indicates the better electrochemical kinetic activity during cycles. The three-dimensional isotropy structure of the amorphous CoS-140 could promote the penetration of the electrolyte and accelerate the diffusion velocity of the lithium ions into the active materials during the lithium storage process (Etacheri et al., 2015; Wu et al., 2018; Wu et al., 2020).

It is necessary to further understand the reason for the fast reaction kinetic and the energy storage mechanism of the amorphous CoS-140 sample. The CV curves with different scan rates $(0.1-3 \mathrm{mV} / \mathrm{s})$ were measured and shown in Figure 7A. The CV curves maintain analogous shapes, while the areas enclosed by the CV curves and the identities of the redox reaction peaks gradually increase with the scan rates, which are always reported by other works of literature (Wu et al., 2019; Duan et al., 2021; Wu et al., 2021). The redox peaks are even evident at the high scan rate of $3 \mathrm{mV} / \mathrm{s}$, indicating the high reaction dynamics (Wang et al., 2020d). The total energy storage of the electrode is generally contributed by two reaction processes of surface capacitive mechanism and diffusion mechanism (Duan et al., 2021), which can be roughly estimated by the following equations (Wang et al., 2020b; Yuan et al., 2020b).

$$
\begin{gathered}
I_{\text {Peak }}=a v^{b} \\
\ln \left(I_{\text {Peak }}\right)=b \ln (v)+\ln a
\end{gathered}
$$

$I_{\text {Peak }}$ represents the currents of the redox peaks at different scan rates marked by the arrows in Figure $7 \mathbf{A}$, and $v$ denotes the corresponding scan rates. $a$ and $b$ are the variable parameters, and generally, the value of $b$ is between 0.5 and one according to the different contribution ratios of the two parts. When $b=0.5$, the electrochemical system is controlled by charge diffusion, while $b=1$, the capacitive behavior is dominant (Wu et al., 2019; Wang et al., 2020b; Jiang et al., 2020; Duan et al., 2021; Wu et al., 2021). According to the linear fitting of $\ln \left(I_{\text {Peak }}\right)$ vs $\ln (v)$ shown in Figure $7 \mathbf{B}$ the values of $b$ for the three redox reaction peaks are $0.68,0.59$, and 0.78 , respectively, which indicates the mixed contribution of surface capacitive effect and diffusioncontrolled process. The quantitative contribution of surface capacitive effect for the electrochemical system can be further analyzed by the following equations (Wu et al., 2019; Duan et al., 2021; Wu et al., 2021).

$$
I=k_{1} v+k_{2} v^{0.5}
$$

$$
\frac{I}{v^{0.5}}=k_{1} v^{0.5}+k_{2}
$$

$k_{1} v$ and $k_{2} v^{1 / 2}$ represent the surface capacitive contribution and the charge diffusion contribution, respectively (Wu et al., 2019; Duan et al., 2021). A series of $k_{1}$ and $k_{2}$ can be obtained by the slope and intercept of $I / v^{0.5}$ vs $\nu^{0.5}$ plots at different voltages. As shown in Figure 7C, the capacity contribution of the surface capacitive effect is $59.7 \%$ for the $\mathrm{CV}$ curves at the scan rate of $1 \mathrm{mV} / \mathrm{s}$. The surface capacitive contributions for the capacities at different scan rates are shown in Figure 7D. The capacitive behavior contribution ratio gradually increases with the increase of the scan rates. The maximum contribution ratio of $79.8 \%$ is achieved at the scan rate of $3.0 \mathrm{mV} / \mathrm{s}$, indicating the dominance of the capacitive behavior at a high scan rate, which is in agreement with the outstanding rate capability. The large contribution ratio of the capacitive behavior could result from the more surface defects and the inside void space of the amorphous structure for the CoS-140 sample, which is beneficial for the enhanced electrochemical performance (Lian et al., 2017; Li et al., 2020a; Liu et al., 2021b).

\section{CONCLUSION}

In summary, through controlling the reaction temperatures, a series of amorphous and crystalline cobalt sulfide nanomaterials were prepared by a facile solvothermal method. Compared to the crystalline cobalt sulfide, the amorphous cobalt sulfide exhibited superior electrochemical performance with the initial discharge and charge capacities of $2,132 \mathrm{mAh} / \mathrm{g}$ and $1,443 \mathrm{mAh} / \mathrm{g}$ at $200 \mathrm{~mA} / \mathrm{g}$. The reversible capacity of $1,245 \mathrm{mAh} / \mathrm{g}$ after 200 cycles was obtained. After discharge-charge cycles at different current densities, the specific capability increased to $1,047 \mathrm{mAh} / \mathrm{g}$ when back to $100 \mathrm{~mA} / \mathrm{g}$. The outstanding electrochemical performance of the amorphous cobalt sulfide nanomaterials could result from the special structural characteristics of amorphous materials. The amorphous cobalt sulfide nanomaterials could be used as anodes for LIBs in the future.

\section{DATA AVAILABILITY STATEMENT}

The raw data supporting the conclusion of this article will be made available by the authors, without undue reservation.

\section{AUTHOR CONTRIBUTIONS}

All authors listed have made a substantial, direct, and intellectual contribution to the work and approved it for publication.

\section{FUNDING}

This work was funded by the National Natural Science Foundation of China No. 22179066 and the Project of Shandong Province Higher Educational Science and Technology Program No. J17KA184. 


\section{REFERENCES}

Duan, Y., Du, S., Tao, H., and Yang, X. (2021). Sn@C Composite for Lithium Ion Batteries: Amorphous vs. Crystalline Structures. Ionics 27, 1403-1412. doi:10.1007/s11581-021-03906-4

Etacheri, V., Hong, C. N., and Pol, V. G. (2015). Upcycling of Packing-Peanuts into Carbon Microsheet Anodes for Lithium-Ion Batteries. Environ. Sci. Technol. 49, 11191-11198. doi:10.1021/acs.est.5b01896

Gao, M., Zhou, W.-Y., Mo, Y.-X., Sheng, T., Deng, Y., Chen, L., et al. (2021). Outstanding Long-Cycling Lithium-sulfur Batteries by Core-Shell Structure of S@Pt Composite with Ultrahigh Sulfur Content. Adv. Powder Mater. doi:10.1016/j.apmate.2021.09.006

Gu, Y., Xu, Y., and Wang, Y. (2013). Graphene-wrapped CoS Nanoparticles for High-Capacity Lithium-Ion Storage. ACS Appl. Mater. Inter. 5, 801-806. doi:10.1021/am3023652

Gu, Z. Y., Guo, J. Z., Zhao, X. X., Wang, X. T., Xie, D., Sun, Z. H., et al. (2021). Highionicity Fluorophosphate Lattice via Aliovalent Substitution as Advanced Cathode Materials in Sodium-ion Batteries. InfoMat 3, 694-704. doi:10.1002/inf2.12184

He, J., Chen, Y., Li, P., Fu, F., Wang, Z., and Zhang, W. (2015). Self-assembled $\mathrm{CoS}_{2}$ Nanoparticles Wrapped by $\mathrm{CoS}_{2}$-Quantum-Dots-Anchored Graphene Nanosheets as superior-capability Anode for Lithium-Ion Batteries. Electrochimica Acta 182, 424-429. doi:10.1016/j.electacta.2015.09.131

Hou, X., Li, W., Wang, Y., Li, S., Meng, Y., Yu, H., et al. (2020). Sodium-based Dual-Ion Batteries via Coupling High-Capacity Selenium/graphene Anode with High-Voltage Graphite Cathode. Chin. Chem. Lett. 31, 2314-2318. doi:10.1016/ j.cclet.2020.04.021

Jiang, W., Liu, Q., Peng, J., Jiang, Y., Ding, Y., and Wei, Q. (2020). $\mathrm{Co}_{9} \mathrm{~S}_{8}$ Nanoparticles Embedded into Amorphous Carbon as Anode Materials for Lithium-Ion Batteries. Nanotechnology 31, 235713. doi:10.1088/1361-6528/ ab7887

Jin, R., Yang, L., Li, G., and Chen, G. (2015). Hierarchical Worm-like $\mathrm{CoS}_{2}$ Composed of Ultrathin Nanosheets as an Anode Material for Lithium-Ion Batteries. J. Mater. Chem. A. 3, 10677-10680. doi:10.1039/C5TA02646F

Jin, R., Zhou, J., Li, G., and Yang, L. (2016). Co 9 S 8 Nanosheet Arrays Supported on Nickel Foam for Enhanced Performance as Anode Material for Li-Ion Batteries. Mater. Lett. 163, 183-186. doi:10.1016/j.matlet.2015.10.093

Li, H., Hu, Z., Xia, Q., Zhang, H., Li, Z., Wang, H., et al. (2021a). Operando Magnetometry Probing the Charge Storage Mechanism of CoO Lithium-Ion Batteries. Adv. Mater. 33, 2006629. doi:10.1002/adma.202006629

Li, L.-W., Wang, L.-P., Zhang, M.-Y., Huang, Q.-Z., He, K.-J., and Wu, F.-X. (2020a). Enhancement of Lithium Storage Capacity and Rate Performance of Se-Modified $\mathrm{MnO} / \mathrm{Mn}_{3} \mathrm{O}_{4}$ Hybrid Anode Material via Pseudocapacitive Behavior. Trans. Nonferrous Met. Soc. China 30, 1904-1915. doi:10.1016/ S1003-6326(20)65349-3

Li, Q., Li, H., Xia, Q., Hu, Z., Zhu, Y., Yan, S., et al. (2021b). Extra Storage Capacity in Transition Metal Oxide Lithium-Ion Batteries Revealed by In Situ Magnetometry. Nat. Mater. 20, 76-83. doi:10.1038/s41563-020-0756-y

Li, S.-F., Gu, Z.-Y., Guo, J.-Z., Hou, X.-K., Yang, X., Zhao, B., et al. (2021c). Enhanced Electrode Kinetics and Electrochemical Properties of Low-Cost $\mathrm{NaFe}_{2} \mathrm{PO}_{4}\left(\mathrm{SO}_{4}\right)_{2}$ via $\mathrm{Ca}_{2+}$ Doping as Cathode Material for Sodium-Ion Batteries. J. Mater. Sci. Technol. 78, 176-182. doi:10.1016/ j.jmst.2020.10.047

Li, W.-H., Liang, H.-J., Hou, X.-K., Gu, Z.-Y., Zhao, X.-X., Guo, J.-Z., et al. (2020b). Feasible Engineering of Cathode Electrolyte Interphase Enables the Profoundly Improved Electrochemical Properties in Dual-Ion Battery. J. Energ. Chem. 50, 416-423. doi:10.1016/j.jechem.2020.03.043

Li, X., Meng, X., Liu, J., Geng, D., Zhang, Y., Banis, M. N., et al. (2012). Tin Oxide with Controlled Morphology and Crystallinity by Atomic Layer Deposition onto Graphene Nanosheets for Enhanced Lithium Storage. Adv. Funct. Mater. 22, 1647-1654. doi:10.1002/adfm.201101068

Li, Z., Zhang, Y., Li, X., Gu, F., Zhang, L., Liu, H., et al. (2021d). Reacquainting the Electrochemical Conversion Mechanism of $\mathrm{FeS}_{2}$ Sodium-Ion Batteries by Operando Magnetometry. J. Am. Chem. Soc. 143, 12800-12808. doi:10.1021/ jacs.1c06115

Lian, Q., Zhou, G., Liu, J., Wu, C., Wei, W., Chen, L., et al. (2017). Extrinsic Pseudocapacitve Li-Ion Storage of SnS Anode via Lithiation-Induced Structural
Optimization on Cycling. J. Power Sourc. 366, 1-8. doi:10.1016/ j.jpowsour.2017.09.009

Liang, H., Zhang, H., Zhao, L., Chen, Z., Huang, C., Zhang, C., et al. (2022). Layered $\mathrm{Fe}_{2}\left(\mathrm{MoO}_{4}\right)_{3}$ Assemblies with Pseudocapacitive Properties as Advanced Materials for High-Performance Sodium-Ion Capacitors. Chem. Eng. J. 427, 131481. doi:10.1016/j.cej.2021.131481

Liu, C., Li, Q., and Wang, K. (2021a). State-of-charge Estimation and Remaining Useful Life Prediction of Supercapacitors. Renew. Sustain. Energ. Rev. 150, 111408. doi:10.1016/j.rser.2021.111408

Liu, H., Hu, R., Sun, W., Zeng, M., Liu, J., Yang, L., et al. (2013). Sn@SnOx/C Nanocomposites Prepared by Oxygen Plasma-Assisted Milling as Cyclic Durable Anodes for Lithium Ion Batteries. J. Power Sourc. 242, 114-121. doi:10.1016/j.jpowsour.2013.05.087

Liu, W., Xiang, P., Dong, X., Yin, H., Yu, H., Cheng, P., et al. (2021b). Two Advantages by a Single Move: Core-Bishell Electrode Design for Ultrahigh-Rate Capacity and Ultralong-Life Cyclability of Lithium Ion Batteries. Composites B: Eng. 216, 108883. doi:10.1016/ j.compositesb.2021.108883

Lu, M., Liao, C., Jiang, C., Du, Y., Zhang, Z., and Wu, S. (2017). Remarkable HighTemperature Performance of Hollow $\mathrm{Co}_{9} \mathrm{~S}_{8}$ Nanoparticles Integrated with Carbon Materials for Lithium-Ion Batteries. Electrochimica Acta 250, 196-202. doi:10.1016/j.electacta.2017.08.019

Lu, Y., Huang, G., Wang, Y., Li, H., Qin, Z., and Lu, X. (2018). Crack-free Fe-Based Amorphous Coating Synthesized by Laser Cladding. Mater. Lett. 210, 46-50. doi:10.1016/j.matlet.2017.08.125

Luo, F., Ma, D., Li, Y., Mi, H., Zhang, P., and Luo, S. (2019). Hollow $\mathrm{Co}_{3} \mathrm{~S}_{4} / \mathrm{C}$ Anchored on Nitrogen-Doped Carbon Nanofibers as a Free-Standing Anode for High-Performance Li-Ion Batteries. Electrochimica Acta 299, 173-181. doi:10.1016/j.electacta.2018.12.175

Ma, Y., Ma, Y., Bresser, D., Ji, Y., Geiger, D., Kaiser, U., et al. (2018). Cobalt Disulfide Nanoparticles Embedded in Porous Carbonaceous Micropolyhedrons Interlinked by Carbon Nanotubes for Superior Lithium and Sodium Storage. ACS Nano 12, 7220-7231. doi:10.1021/acsnano.8b03188

Qiu, W., Jiao, J., Xia, J., Zhong, H., and Chen, L. (2015). A Self-Standing and Flexible Electrode of Yolk-Shell CoS2Spheres Encapsulated with NitrogenDoped Graphene for High-Performance Lithium-Ion Batteries. Chem. Eur. J. 21, 4359-4367. doi:10.1002/chem.201405821

Shi, M., Wang, Q., Hao, J., Min, H., You, H., Liu, X., et al. (2020). MOF-derived Hollow $\mathrm{Co}_{4} \mathrm{~S}_{3} / \mathrm{C}$ Nanosheet Arrays Grown on Carbon Cloth as the Anode for High-Performance Li-Ion Batteries. Dalton Trans. 49, 14115-14122. doi:10.1039/d0dt03070h

Shi, W., Zhu, J., Rui, X., Cao, X., Chen, C., Zhang, H., et al. (2012). Controlled Synthesis of Carbon-Coated Cobalt Sulfide Nanostructures in Oil Phase with Enhanced Li Storage Performances. ACS Appl. Mater. Inter. 4, 2999-3006. doi:10.1021/am3003654

Sun, B., Chen, Z., Kim, H.-S., Ahn, H., and Wang, G. (2011). MnO/C Core-Shell Nanorods as High Capacity Anode Materials for Lithium-Ion Batteries. J. Power Sourc. 196, 3346-3349. doi:10.1016/j.jpowsour.2010.11.090

Sun, B., Horvat, J., Kim, H. S., Kim, W.-S., Ahn, J., and Wang, G. (2010). Synthesis of Mesoporous $\alpha-\mathrm{Fe}_{2} \mathrm{O}_{3}$ Nanostructures for Highly Sensitive Gas Sensors and High Capacity Anode Materials in Lithium Ion Batteries. J. Phys. Chem. C 114, 18753-18761. doi:10.1021/jp102286e

Wang, G., Yue, H., Jin, R., Wang, Q., and Gao, S. (2020a). $\mathrm{Co}_{3} \mathrm{~S}_{4}$ Ultrathin Nanosheets Entangled on N-Doped Amorphous Carbon Coated Carbon Nanotubes with C S Bonding for High Performance Li-Ion Batteries. J. Electroanalytical Chem. 858, 113794. doi:10.1016/j.jelechem.2019.113794

Wang, L.-H., Dai, Y.-K., Qin, Y.-F., Chen, J., Zhou, E.-L., Li, Q., et al. (2020b). OnePot Synthesis and High Electrochemical Performance of $\mathrm{CuS} / \mathrm{Cu}_{1.8} \mathrm{~S}$ Nanocomposites as Anodes for Lithium-Ion Batteries. Materials 13, 3797. doi: $10.3390 / \mathrm{ma1} 13173797$

Wang, L.-H., Gao, S., Ren, L.-L., Zhou, E.-L., and Qin, Y.-F. (2021a). The Synergetic Effect Induced High Electrochemical Performance of $\mathrm{CuO} / \mathrm{Cu}_{2} \mathrm{O} / \mathrm{Cu}$ Nanocomposites as Lithium-Ion Battery Anodes. Front. Chem. 9. doi:10.3389/fchem.2021.790659

Wang, L.-H., Teng, X.-L., Qin, Y.-F., and Li, Q. (2021b). High Electrochemical Performance and Structural Stability of $\mathrm{CoO}$ nanosheets/CoO Film as SelfSupported Anodes for Lithium-Ion Batteries. Ceramics Int. 47, 5739-5746. doi:10.1016/j.ceramint.2020.10.160 
Wang, M., Fan, L., Sun, X., Guan, B., Jiang, B., Wu, X., et al. (2020c). NitrogenDoped $\mathrm{CoSe}_{2}$ as a Bifunctional Catalyst for High Areal Capacity and Lean Electrolyte of Li-S Battery. ACS Energ. Lett. 5, 3041-3050. doi:10.1021/ acsenergylett.0c01564

Wang, Y., Cao, L., Li, J., Kou, L., Huang, J., Feng, Y., et al. (2020d).Cu/Cur O@ Ppy Nanowires as a Long-Life and High-Capacity Anode for Lithium Ion Battery. Chem. Eng. J. 391, 123597. doi:10.1016/j.cej.2019.123597

Wu, C., Zhao, Y., Fan, Q., Kuang, Q., and Dong, Y. (2021). Facile Synthesis and Electrochemical Properties of Amorphous/crystalline $\mathrm{VO}\left(\mathrm{PO}_{3}\right)_{2} @ \mathrm{C}$ as the Anodes for Lithium-Ion Battery. J. Electroanalytical Chem. 895, 115541. doi:10.1016/j.jelechem.2021.115541

Wu, H., Qin, M., Wang, W., Cao, Z., Liu, Z., Yu, Q., et al. (2018). Ultrafast Synthesis of Amorphous VOxembedded into 3D Strutted Amorphous Carbon Frameworks-Short-Range Order in Dual-Amorphous Composites Boosts Lithium Storage. J. Mater. Chem. A. 6, 7053-7061. doi:10.1039/C8TA00654G

Wu, H., Zhang, Z., Qin, M., Wang, Q., Cao, Z., Yu, Y., et al. (2019). Solution Combustion Synthesis of Crystalline $\mathrm{V}_{2} \mathrm{O}_{3}$ and Amorphous $\mathrm{V}_{2} \mathrm{O}_{3} / \mathrm{C}$ as Anode for Lithium-ion Battery. J. Am. Ceram. Soc. 103, 2643-2652. doi:10.1111/ jace. 16962

Wu, H., Zhou, S., Tseng, C., Qin, M., Shiue, A., Chu, A., et al. (2020). One-pot Solution Combustion Synthesis of Crystalline and Amorphous Molybdenum Trioxide as Anode for Lithium-ion Battery. J. Am. Ceram. Soc. 104, 1102-1109. doi:10.1111/jace.17499

Yan, J. M., Huang, H. Z., Zhang, J., Liu, Z. J., and Yang, Y. (2005). A Study of Novel Anode Material $\mathrm{CoS}_{2}$ for Lithium Ion Battery. J. Power Sourc. 146, 264-269. doi:10.1016/j.jpowsour.2005.03.144

Yu, L., Yang, J. F., and Lou, X. W. D. (2016). Formation of $\mathrm{CoS}_{2}$ Nanobubble Hollow Prisms for Highly Reversible Lithium Storage. Angew. Chem. Int. Ed. 55, 13422-13426. doi:10.1002/anie.201606776

Yuan, C., Lu, D., An, Y., and Bian, X. (2020a). A Nanocomposite of Si@C Nanosphere and Hollow Porous $\mathrm{Co}_{9} \mathrm{~S}_{8} / \mathrm{C}$ Polyhedron as High-Performance Anode for Lithium-Ion Battery. ChemElectroChem 7, 4423-4430. doi:10.1002/ celc. 202001052

Yuan, H., Wang, F., Li, S., Lin, Z., and Huang, J. (2020b). A Cellulose Substance Derived Nanofibrous CoS-Nanoparticle/carbon Composite as a HighPerformance Anodic Material for Lithium-Ion Batteries. New J. Chem. 44, 1846-1857. doi:10.1039/c9nj05587h

Zhang, F., Teng, X., Shi, W., Song, Y., Zhang, J., Wang, X., et al. (2020a). $\mathrm{SnO}_{2}$ Nanoflower Arrays on an Amorphous Buffer Layer as Binder-free Electrodes for Flexible Lithium-Ion Batteries. Appl. Surf. Sci. 527, 146910-146920. doi:10.1016/j.apsusc.2020.146910

Zhang, P., Tian, R., Cao, M., Feng, Y., and Yao, J. (2020). Embedding $\mathrm{Co}_{9} \mathrm{~S}_{8}$ Nanoparticles into Porous Carbon Foam with High Flexibility and Enhanced
Lithium Ion Storage. J. Electroanalytical Chem. 863, 114062. doi:10.1016/ j.jelechem.2020.114062

Zhang, Y., Wang, P., Yin, Y., Liu, N., Song, N., Fan, L., et al. (2019a). Carbon Coated Amorphous Bimetallic Sulfide Hollow Nanocubes towards Advanced Sodium Ion Battery Anode. Carbon 150, 378-387. doi:10.1016/j.carbon.2019.05.048

Zhang, Y., Wang, P., Yin, Y., Zhang, X., Fan, L., Zhang, N., et al. (2019b). Heterostructured SnS-ZnS@C Hollow Nanoboxes Embedded in Graphene for High Performance Lithium and Sodium Ion Batteries. Chem. Eng. J. 356, 1042-1051. doi:10.1016/j.cej.2018.09.131

Zhao, S., Yan, K., Zhang, J., Sun, B., and Wang, G. (2021). Reaction Mechanisms of Layered Lithium-Rich Cathode Materials for High-Energy Lithium-Ion Batteries. Angew. Chem. Int. Ed. 60, 2208-2220. doi:10.1002/anie.202000262

Zhao, Z., Hu, Z., Jiao, R., Tang, Z., Dong, P., Li, Y., et al. (2019). Tailoring Multi-Layer Architectured $\mathrm{FeS}_{2} @ \mathrm{C}$ Hybrids for superior Sodium-, Potassium- and AluminumIon Storage. Energ. Storage Mater. 22, 228-234. doi:10.1016/j.ensm.2019.01.022

Zhao, Z., Hu, Z., Li, Q., Li, H., Zhang, X., Zhuang, Y., et al. (2020). Designing TwoDimensional $\mathrm{WS}_{2}$ Layered Cathode for High-Performance Aluminum-Ion Batteries: From Micro-assemblies to Insertion Mechanism. Nano Today 32, 100870. doi:10.1016/j.nantod.2020.100870

Zhou, Y., Wang, Y., Wang, K., Kang, L., Peng, F., Wang, L., et al. (2020). Hybrid Genetic Algorithm Method for Efficient and Robust Evaluation of Remaining Useful Life of Supercapacitors. Appl. Energ. 260, 114169-114184. doi:10.1016/ j.apenergy.2019.114169

Zhou, Y., Yan, D., Xu, H., Feng, J., Jiang, X., Yue, J., et al. (2015). Hollow Nanospheres of Mesoporous $\mathrm{Co}_{9} \mathrm{~S}_{8}$ as a High-Capacity and Long-Life Anode for Advanced Lithium Ion Batteries. Nano Energy 12, 528-537. doi:10.1016/j.nanoen.2015.01.019

Conflict of Interest: The authors declare that the research was conducted in the absence of any commercial or financial relationships that could be construed as a potential conflict of interest.

Publisher's Note: All claims expressed in this article are solely those of the authors and do not necessarily represent those of their affiliated organizations, or those of the publisher, the editors and the reviewers. Any product that may be evaluated in this article, or claim that may be made by its manufacturer, is not guaranteed or endorsed by the publisher.

Copyright (C) 2022 Ren, Wang, Qin and Li. This is an open-access article distributed under the terms of the Creative Commons Attribution License (CC BY). The use, distribution or reproduction in other forums is permitted, provided the original author(s) and the copyright owner(s) are credited and that the original publication in this journal is cited, in accordance with accepted academic practice. No use, distribution or reproduction is permitted which does not comply with these terms. 